\title{
FUNDAMENTOS TEÓRICOS PARA UMA APROXIMAÇÃO AO ESTUDO DA EDUCAÇÃO PROFISSIONAL
}

\author{
T. C. Sabino; J. Deribaldo G. dos Santos; Zuleide F de Queiroz \\ tcs54@hotmail.com1; deribaldo.santos@uece.br; zuleide.queiroz@urca.br \\ 10.15628/rbept.2017.6057 \\ Artigo submetido em jun/2017 e aceito em set/2017
}

\section{RESUMO}

O presente estudo visa contribuir para a compreensão da relação entre trabalho e educação na perspectiva de uma educação comprometida com o desenvolvimento pleno das capacidades humanas. Realizamos uma breve discussão com autores referenciados na ótica marxista, pois estes adeptos do socialismo-científico criticam a dualidade histórica da educação de dedicarem ensino técnico para os jovens da classe trabalhadora enquanto os filhos das classes mais abastadas seguem com uma formação de caráter propedêutico para serem os futuros dirigentes da sociedade.

Palavras-Chaves: Trabalho, Educação.

\section{RESUMEN}

Este estudio tiene como objetivo contribuir a la comprensión de la relación entre el trabajo y la educación en la perspectiva de una educación comprometida con el desarrollo pleno de las capacidades humanas. Hemos llevado a cabo una breve discusión con los autores guiados por la perspectiva marxista, pues estos adeptos del socialismo científico critican la dualidad histórica de dedicar la educación técnica para los jóvenes de la clase obrera, mientras que los hijos de las clases más ricas siguen con una formación de carácter general para ser los futuros líderes de la sociedad.

Palabras Clave: Trabajo, Educación. 


\section{INTRODUÇÃO}

A proposta de Educação Profissional integrada ao Ensino Médio vem sendo adotada em todo o país como uma proposta para efetivar a indissociabilidade entre formação geral e profissional na perspectiva da educação integral. Para contribuir numa análise preliminar desta política, recuperaremos os aspectos fundamentais sobre o trabalho e sua relação com a educação.

Para embasar nossa discussão, necessitaremos visitar obras clássicas de Marx e Engels, assim como de estudiosos da teoria marxista, tais como Manacorda (1991), Ponce (2005), Suchodolski (1984), Saviani (1994, 2007), Lessa e Tonet (2008) e Jimenez e Lima (2011), entre outros. Apoiamo-nos nesses autores para buscar uma explicação materialista para a diferenciação entre os homens e os animais, levando em consideração o papel do trabalho como o ato-gênese do homem como ser social.

\section{TRABALHO HUMANO E EDUCAÇÃO EM PERSPECTIVA MARXISTA}

No contexto da atual divisão internacional do trabalho, nosso país assume a posição de exportador de matéria-prima para o mercado mundial, em especial para a China, e exportador de produtos manufaturados para os países da América Latina. Além disso, e para ajudar a cumprir esse objetivo, muitas empresas estão se instalando em novas localidades, a exemplo das cidades nordestinas, necessitando, assim, de mão de obra minimamente qualificada para garantia de uma produção "competitiva" no mercado interno e mundial.

Nesse ambiente, avança a passos largos o Ensino Médio Integrado à Educação Profissional. Além do mais, as escolas profissionais de nível médio cumprem, na prática, dois objetivos:

a) Servir de redentora dos problemas sociais sofridos pelos jovens estudantes da escola pública, ou pelo menos de esperança para solução desses problemas;

b) Aparecer para a sociedade como escola-modelo, padrão a ser seguido pelas demais escolas públicas, uma vez que nem todos se matriculam nessa modalidade de ensino para garantir uma profissão, senão para aumentar as chances de aprovação em testes de ingresso para instituições de ensino superior, públicas em especial.

Portanto, é urgente para nossa temática compreender a verdadeira e profunda natureza do trabalho, assim como ele se relaciona com a educação no atual contexto capitalista.

\section{A FUNDAMENTAL DIFERENÇA ENTRE OS HOMENS E OS ANIMAIS}

Se há um traço comum entre todas as sociedades ou comunidades humanas é o fato de, para poderem existir, os homens tiveram que transformar a natureza a todo o momento. Esse é um pressuposto do pensamento de Marx que pode ser comprovado historicamente, visto que em nenhuma sociedade humana o homem pode prescindir do intercâmbio com a natureza para garantir sua reprodução. Porém, as leis que regem a natureza não se aplicam ao mundo dos homens, pois a reprodução biológica da espécie, mesmo indispensável para sua continuidade, é somente um dos aspectos de sua perpetuação. Diferente dos animais, a dimensão social na vida dos homens cumpre um papel primordial na compreensão de sua história e nas condições de sua reprodução. Essa dimensão social compreende a ciência, a arte, a cultura, a política, a luta de classes, os sentimentos, etc. 
Com isso, os homens se colocam na posição de construírem sua própria história, de serem protagonistas do futuro de sua espécie, de todas as outras espécies e até mesmo do planeta Terra. A partir do trabalho, os homens criam as bases para se constituírem enquanto indivíduos, ou seja, se diferenciam da natureza enquanto seres sociais. Por isso, podemos falar que são distintas as leis que regem o desenvolvimento histórico e os processos naturais.

0 trabalho que aqui nos referimos tem um aspecto qualitativamente distinto da atividade desenvolvida, por exemplo, pelas abelhas e pelas formigas. Estas desenvolvem suas atividades baseadas em funções biológicas ou genéticas, isto é, o tempo não é capaz de mudá-las ou evoluí-las, continuando sempre as mesmas ao longo da história. Portanto, essa atividade não desenvolve esses insetos para um tipo de inseto com capacidades superiores.

Os homens, ao contrário, se tornam superiores no processo de trabalho, adquirem experiências após cada processo. Mas porque o mesmo não ocorre com os outros animais? Por simples motivo: o homem tem a capacidade de antecipar suas ações e seus resultados em sua mente, em sua consciência, antes de colocá-las em prática. Para Marx, a diferença do homem em relação à natureza é que a evolução humana se assenta nessa capacidade de criar ideias (prévia-ideação) antes de construí-las materialmente (objetivação).

O resultado dessa objetivação será sempre algum tipo de transformação da realidade. Como toda objetivação gera uma nova situação, já que a realidade mudou em algum aspecto, o indivíduo também já não pode ser considerado o mesmo. Em algum aspecto, ele também se modificou. Em uma próxima objetivação de mesmo gênero, ele já não parte mais do mesmo ponto, mas sim, de um ponto mais avançado, baseado na experiência anterior.

A abelha não produz um mel mais saboroso ou nutritivo após a primeira produção. De maneira geral, tende a produzir um mel com as mesmas qualidades, mudando apenas quando condições exteriores a si assim determinarem, mas não devido a sua própria préviaideação consciente e sua objetivação intencional. Por isso, não evoluem a partir de suas experiências concretas e pensadas. Já o homem, ao transformar a natureza, também se transforma, adquirindo novas habilidades e novos conhecimentos. E, como numa reação em cadeia, essa nova situação gera novas necessidades e novas possibilidades de satisfazêlas. Assim, "como toda objetivação origina uma nova situação, a história jamais se repete" (LESSA e TONET, 2008, p. 20).

Há que ressaltarmos o caráter objetivo do próprio processo de prévia-ideação. 0 homem ao projetar em sua mente um objeto de trabalho, uma faca, por exemplo, precisou sentir a necessidade real e concreta de um instrumento cortante. Quer dizer, o processo consciente e subjetivo de idealizar uma faca antes mesmo de sua materialização, também foi precedido da necessidade objetiva e material de um objeto com a função de cortar.

Através do trabalho, isto é, da transformação da natureza, o homem também se transforma. Portanto, o trabalho diferencia o homem dos outros animais tornando-o um ser não somente animal, mas um ser social. É por meio dele que a humanidade produz a base material da sociedade.

Discorremos, até aqui, tratando o trabalho em termos de sua relação e suas consequências para o indivíduo. Mas como esse indivíduo é, na verdade, um ser social, seu trabalho e o fruto dele se relacionam também com o conjunto da sociedade. Não há um indivíduo que exista fora da sociedade (por isso mesmo deve ser considerado um ser social), mesmo considerando a mais primitiva das sociedades. Dessa forma, a discussão 
desse processo complexo do trabalho humano tem de levar, também, esse aspecto em consideração, sob o risco de fantasiar a discussão.

Aproveitamos para ressaltar que o estudante da escola profissionalizante sairá da escola habilitado para exercer uma determinada profissão numa sociedade marcada pela divisão em classes sociais de interesses antagônicos e irreconciliáveis. Mas a propaganda oficial, muito bem assimilada pela consciência média e pelo senso comum, afırma que essa oportunidade é a grande chance do primeiro emprego, já com a carteira de trabalho assinada, e de ascensão social. Entretanto, até que ponto os cursos profissionalizantes oferecidos pelas escolas em tempo integral no país são uma necessidade do capital para se reproduzir e garantir suas taxas de lucro ao invés de cumprir com a função de desenvolvimento das capacidades humanas nos campos intelectual, científico, artístico, político, filosófico, etc.?

Retomando nosso exemplo da faca, notamos que não só o indivíduo que a projetou e a materializou se desenvolveu e evoluiu após esse processo. Os outros indivíduos da sociedade e a própria sociedade, também se modificaram nesse percurso. Outro indivíduo pode, agora, a partir da experiência de outrem, gerar uma nova ideia que atenda a uma nova necessidade. Isso quer dizer: numa relação dialética, o novo objeto tanto influencia a sociedade quanto passa a sofrer influência dela.

A descoberta de uma nova faca, assim como de qualquer outro instrumento de trabalho, é decisiva para a história da humanidade ao aumentar capacidade produtiva e possibilitar o desenvolvimento. Percebe-se que novas descobertas partem de descobertas anteriores e também constituem o germe dos próximos passos da evolução humana.

Quando há uma nova descoberta não só o autor dela se encontra diante de um novo fato, mas toda a sociedade precisa encarar essa nova realidade e as consequências por ela geradas. Referimo-nos aqui às novas possibilidades e necessidades coletivas que surgirão desse processo, fazendo com que ambos, o novo objeto e a sociedade, evoluam nesse percurso.

Esse processo constante de descobertas de novos instrumentos de trabalho e de novas necessidades e possibilidades, ao longo de milênios, aumentou bastante a capacidade do homem de produzir sua própria existência material. A velocidade com a qual o homem, nos dias atuais, transforma a natureza, ou seja, utiliza os seus recursos naturais, põe inclusive em discussão a possibilidade de esgotamento desses recursos. Esse avanço das forças produtivas se intensificou bastante com o advento do capitalismo, que se caracteriza, sobretudo, por ser um sistema de produção em escala mundial.

\section{A RELAÇÃO TRABALHO E EDUCAÇÃO}

Assim, como o trabalho, a educação também se constitui como uma atividade genuinamente humana. Isso quer dizer que, para sermos rigorosos, somente o homem é capaz de trabalhar e de educar. Essa afırmação admite a existência de características que sejam próprias à espécie humana. Essa característica essencial, por sua vez, explicaria o trabalho e a educação como atributos do homem, deixando aberta a possibilidade de que estes sejam considerados apenas como atributos acidentais.

Na filosofia existiram e existem tentativas de definição do homem. Uma das mais conhecidas é a de Aristóteles, que definiria o homem como um animal racional. Nesse modo de pensar, trabalho e educação, mesmo sendo atributos especificamente humanos, aparecem como de caráter acidental e não substancial. 
Outras tentativas também expressam essa mesma visão, tais como "o homem é um animal político", "é um animal simbólico", "um animal que fala", "o homem não é senão sua alma", "o homem é apenas corpo", "é uma substância composta de dois elementos incompletos e complementares, o corpo e a alma", "é um espírito encarnado". Todas elas encerram uma visão "[...] marcada por um caráter especulativo e metafísico contraposto à existência histórica dos homens. Partem de uma ideia abstrata e universal de essência humana [...]" (SAVIANI, 2007, p. 154).

Em sua obra A pedagogia e as grandes correntes filosóficas, Suchodolski (1984) aborda o conflito entre duas tendências pedagógicas fundamentais, uma baseada na essência do homem e outra baseada na existência do homem, cada qual correspondendo a uma grande corrente da filosofia. A primeira e mais antiga destas doutrinas assenta numa concepção ideal de homem, racionalista em Platão e cristã em São Tomás de Aquino. A segunda, por sua vez, toma o homem tal como ele é e não como deveria ser.

Ao longo de sua exposição, o autor mostra o nascimento de uma concepção ativa que não se baseia em nenhuma das duas concepções tradicionais, mas sim na compreensão de que o homem é o criador do seu próprio meio, de si mesmo. Para ele, seria o surgimento de uma pedagogia socialista, em oposição e superação à velha pedagogia da essência e da "pedagogia burguesa" da existência do homem.

Apoiados nessa compreensão, entendemos que, para melhor entender o homem, há de se partir das condições materiais concretas nas quais ele está situado. Voltando ao aspecto que diferencia os homens dos animais, notamos que para garantir sua existência o homem sente-se obrigado a se destacar da natureza e produzir sua própria existência material, sua própria vida. Diferentemente dos animais, os homens adaptam a natureza às suas necessidades agindo sobre ela e transformando-a através do trabalho, enquanto os animais se adaptam às condições impostas pela natureza. Escreveram Marx e Engels (1989, p. 13, grifos do original) em meados da década de 1840:

Pode-se distinguir os homens dos animais pela consciência, pela religião e por tudo o que se queira. Mas eles próprios começam a se distinguir dos animais logo que começam a produzir seus meios de existência, e esse passo à frente é a própria consequência de sua organização corporal. Ao produzirem seus meios de existência, os homens produzem indiretamente sua própria vida material.

A ação do homem sobre a natureza, usufruindo-a de acordo com suas necessidades e desejos, é conhecida como trabalho. Assim, é o trabalho que se constitui como a essência humana:

A essência humana não é, então, dada ao homem; não é uma dádiva divina ou natural; não é algo que precede a existência do homem. Ao contrário, a essência humana é produzida pelos próprios homens. o que o homem é, é-o pelo trabalho. A essência do homem é um feito humano. É um trabalho que se desenvolve, se aprofunda e se complexifica ao longo do tempo: é um processo histórico (SAVIANI, 2007, p. 154). 
As concepções anteriormente expostas trazem uma concepção de essência humana externa à existência material do homem. Porém, é justamente no movimento real de criação de sua existência efetiva que os homens se constituem enquanto tal. Portanto, os homens coincidem, por assim dizer, com o que produzem e com o modo como produzem.

O homem precisa transformar a natureza para garantir sua existência. Isto quer dizer que a natureza não garante sua existência como uma dádiva divina ou natural. Dessa maneira, o homem se faz homem por meio do trabalho, se torna homem por meio dele. Assim, o homem não nasce homem, ele forma-se homem. Todavia, também não há no DNA humano nada que possa comprovar sua capacidade de se produzir enquanto homem. É preciso que ele aprenda a produzir sua própria existência. Destarte, a produção do homem é, simultaneamente, a formação do próprio homem, ou seja, um processo educativo, induzindo então que a educação tem origem juntamente com a origem do homem.

Então, logo na linha de partida, existe uma relação de identidade entre trabalho e educação. Como os homens aprendiam a produzir? Produzindo. Como aprendiam a trabalhar? Trabalhando. Assim, vejamos: "Para aprender a manejar o arco, a criança caçava; para aprender a guiar um barco, navegava. As crianças se educavam tomando parte nas funções da coletividade" (PONCE, 2005, p. 19). Os homens educavam-se e educavam as novas gerações à medida que lidavam com a natureza, relacionando-se uns com os outros. Sua aprendizagem era um tanto quanto empírica, conforme determinadas experiências tinham garantida sua validade prática à vida na comunidade, elas deveriam ser repassadas de geração em geração, ao passo que as experiências que tinham pouca serventia prática deveriam ser deixadas de lado.

A sua educação não estava confiada a ninguém em especial, e sim à vigilância difusa do ambiente. Mercê de uma insensível e espontânea assimilação do seu meio ambiente, a criança ia pouco a pouco se amoldando aos padrões reverenciados pelo grupo. A convivência diária que mantinha com os adultos a introduziam nas crenças e práticas que o seu grupo social tinha por melhores. Presa, às costas de sua mãe, metida dentro de um saco, a criança percebia a vida da sociedade que a cercava e compartilhava dela, ajustando-se ao seu ritmo e às suas normas e, como sua mãe andava sem cessar de um lado para o outro, o aleitamento durava vários anos, a criança adquiria sua primeira educação sem que ninguém a dirigisse expressamente.

Como ainda não havia divisão de classes nem propriedade privada, a apropriação da terra e dos produtos do trabalho se dava coletivamente. A terra, constituindo-se como propriedade tribal, garantia ao homem trabalhar e aprender no trabalho. Dessa maneira, ao prover sua existência, o homem também provia sua educação para a vida. Havia uma unidade da educação com o próprio processo de trabalho. A tese de "educar para a vida" tinha seu caráter prático nesse período da História.

Portanto, vemos que a educação é indispensável em todos os modos de organização social, desde a sociedade primitiva, pois seu objetivo, considerada em sentido lato, consiste em reproduzir no indivíduo as objetivações produzidas ao longo do desenvolvimento humano e, dessa forma, possibilitar a continuidade do ser humano enquanto ser social.

Aproveitando o ensejo da apresentação do sentido lato de educação, exporemos brevemente o significado de seu sentido estrito. Tal como vimos, nos primórdios da sociedade humana, a educação surge como um complexo universal e efetiva-se espontaneamente, 
garantido, assim, a perpetuidade do gênero humano. Porém, com a complexificação do trabalho e sua consequente divisão, acompanhada da divisão da sociedade entre classes, essa forma espontânea de educar se torna insuficiente para as demandas originárias dos interesses das classes dominantes.

Acontece que as novas formas de organização do trabalho exigem ainda mais que os indivíduos tenham uma formação própria e específica para exercerem determinadas funções laborais ou sociais, a qual a educação espontânea não mais responde. Assim, o complexo educacional evolui de seu caráter universal, em sentido amplo, para o sentido estrito, devido à força da divisão de classes e influenciada pelos interesses de classe. Essa evolução consiste em que "a educação em sentido estrito surge como uma diferenciação no interior da educação em sentido lato, mas não a substitui. O que se estabelece efetivamente é uma relação de mútua influência entre ambas" (JIMENEZ e LIMA, 2011, p. 88).

Enquanto a educação em sentido lato ocorre de forma espontânea e atende a interesses universais (continuidade do ser social), em sentido estrito ela acontece de maneira intencional e atende a interesses de classe particulares. Outra diferença capital entre essas duas formas de educação é o fato de que, em seu sentido lato, a educação acontece livremente pela síntese dos atos individuais dos membros da sociedade. Em sentido estrito, é norteada predominantemente por um grupo particular, a exemplo da influência que o Banco Mundial (uma instituição notadamente conhecida como organismo imperialista) tem sobre a política educacional dos países dependentes nos dias contemporâneos.

Como o desenvolvimento da produção conduziria à divisão do trabalho e, consequentemente, à apropriação da terra, rompendo a unidade trabalho-educação reinante nas comunidades primitivas, a terra deixa de ser propriedade da tribo e passa a existir a partir da apropriação privada. Nesse momento, a terra constituía o principal meio de produção, ocasionando, como já exposto, a divisão da sociedade em classes sociais antagônicas: proprietários e não proprietários.

Sendo o trabalho a essência humana, fica evidente que o homem não pode viver sem trabalhar, sem prover sua própria existência física. Entretanto, com o surgimento das classes e do aprofundamento da divisão do trabalho na sociedade a partir delas, um pequeno grupo passa a desempenhar outras tarefas que não as de produção. Enquanto que a maioria, não proprietária, continua a desenvolver a missão de garantir a subsistência do conjunto do grupo.

Assim, os proprietários adquirem a condição de poder existir sem trabalhar diretamente e passam a viver preponderantemente do trabalho de outrem. Assumem posição de organizar a produção, defender militarmente a ordem, etc. Os donos da terra convertemse em senhores. "O soberano e a sua família, os funcionários e os magos, os sacerdotes e os guerreiros passaram, desde esse momento, a constituir uma classe compacta, com interesses comuns, em grande parte opostos ao do grupo total” (PONCE, 2005, p. 32).

Essa divisão dos homens em classes produzirá uma divisão na educação também. A unidade antes existente entre educação e trabalho inicia sua ruptura nesse momento. Na Roma antiga, existiam patrícios, guerreiros, plebeus e escravos, mas o trabalho é realizado predominantemente pelos escravos, caracterizando esse modo de produção como modo de produção escravista. Na Idade Média, percebe-se o mesmo. Existiam senhores feudais, vassalos, membros de corporações, artesãos e servos, mas o trabalho é realizado predominantemente pelos servos no feudo do senhor, caracterizando esse modo de produção como modo de produção feudal. 
Seguem as palavras de Saviani $(2007$, p. 155) a respeito da separação entre educação e trabalho:

A partir do escravismo antigo passaremos a ter duas modalidades distintas e separadas de educação: uma para a classe proprietária, identificada como a educação dos homens livres, e outra para a classe não-proprietária, identificada como a educação dos escravos e serviçais. A primeira, centrada nas atividades intelectuais, na arte da palavra e nos exercícios físicos de caráter lúdico e militar. E a segunda, assimilada ao próprio processo de trabalho.

No contexto desse primeiro tipo de educação, ainda segundo Saviani (2007), surge a escola, que, etimologicamente, do grego, significa o lugar do ócio. Os que dispunham de tempo livre podiam frequentar esse local para desenvolver suas capacidades intelectuais. Antes, a educação de todos os membros da sociedade se dava pelo processo de trabalho. Agora, desenvolve-se um tipo peculiar de educação, contraposta a aquela ligada à produção. Essa nova forma de educar, vinculada à escola, passa a ser compreendida com a educação propriamente dita, aprofundando, assim, a sua separação com o trabalho.

Com o surgimento da sociedade de classes, a educação começa a se institucionalizar, acompanhando e influenciando o processo gradativo da divisão do trabalho. Recordemos que, na fase primitiva da humanidade, na qual a produção era coletiva, a educação se dava ao longo da vida (educação espontânea, cotidiana: lato), sem diferenciação das outras atividades desenvolvidas pelo homem, inclusive o trabalho. Após a divisão da sociedade em classes, a educação também resulta cindida entre a da classe dominante e a da classe dominada. A classe dominante passa a ser educada na escola (educação escolar, sistematizada: estrita ) devido seu tempo livre por viver da produção alheia, ao passo que a maioria da sociedade continua a aprender durante a vida e no processo de produção.

Eis aqui um dos primeiros papeis da escola: formar na arte das palavras e da oratória a classe dirigente para condução da sociedade e para sua perpetuação no poder:

A separação entre instrução e trabalho, a discriminação entre a instrução para os poucos e o aprendizado do trabalho para os muitos, e a definição da instrução "institucionalizada" como institutio oratoria, isto é, como formação do governante para a arte da palavra entendida como arte de governar (o "dizer", ao qual se associa a arte das armas, que é o "fazer" dos dominantes); trata-se, também, da exclusão dessa arte de todo indivíduo das classes dominadas, considerado um "charlatão demagogo", um meduti. A consciência da separação entre as duas formações do homem tem a sua expressão literária nas chamadas "sátiras dos ofícios". Logo esse processo de inculturação se transforma numa instrução que cada vez mais define o seu lugar como uma "escola", destinada à transmissão de uma cultura livresca codificada, numa áspera e sádica relação pedagógica (MANACORDA, 1991, p. 356).

Também no intuito de ilustrar esse processo, recorremos novamente a Saviani (1994, p. 162):

[...] a escola, desde suas origens, foi posta do lado do trabalho intelectual; constituiu-se num instrumento para a preparação dos futuros dirigentes que se exercitavam não apenas nas funções 
da guerra (liderança militar), mas também nas funções de mando (liderança política), por meio do domínio da arte da palavra e do conhecimento dos fenômenos naturais e das regras de convivência social.

$\mathrm{Na}$ Antiguidade greco-romana, o Estado desempenhava um importante papel na educação formal. Já na Idade Média, essa função era cumprida pela Igreja Católica. Contudo, nesses dois períodos da história, as funções práticas e manuais não exigiam preparo escolar. A formação dos não proprietários ocorria concomitantemente ao exercício de suas funções. Mesmo no artesanato medieval, em que se exigia uma maior especialização, o aprendizado dava-se nas próprias corporações de ofício, onde o aprendiz dominava o ofício na prática ao lado dos oficiais, com a orientação do mestre, o chamado "mestre de ofício".

Tanto na Antiguidade quanto na Idade Média, o meio de produção dominante era a terra, e a forma econômica dominante era a agricultura. Na Roma e na Grécia, a vida cotidiana era na cidade, mas a sobrevivência vinha do campo, porque era o trabalho agrícola, nos arredores da cidade, que supria as necessidades dos habitantes da cidade. Na Idade Média, a vida era no campo e a sobrevivência vinha também do campo. Até aqui, a forma escolar de educação era secundária enquanto que a forma dominante de educação se dava ligada ao ato de trabalhar (SAVIANI, 1994, p. 152).

No feudalismo, a produção no campo era centrada nas necessidades dos membros da sociedade feudal, isto é, era de baseada na subsistência, na produção de valores de uso. Somente o eventual excedente era destinado à troca. Porém, à medida que as forças produtivas desenvolviam-se, esse excedente se tornava cada vez mais constante e maior quantitativamente, sendo ele o germe do comércio que acontecia nos burgos, que se desenvolvia fora das muralhas do núcleo urbano primitivo, senhorial. Os burgos desenvolveramse pelo processo de troca de produtos entre um feudo e outro. Os produtores levavam seus produtos até o burgo e lá faziam uma espécie de feira trocando seus produtos por outros ou por dinheiro. Os habitantes dos burgos dedicavam-se ao comércio e à produção artesanal. Seus habitantes eram chamados de burgueses, crescendo em poder econômico de modo que, entre muitos outros fatores, no século XIX formaram a burguesia.

O desenvolvimento do comércio criou as condições para a acumulação primitiva, deslocando o eixo do processo produtivo do campo para a cidade, da agricultura para a indústria, que converte o saber de potência intelectual em potência material (SAVIANI, 2007). Desse processo, nascerá a sociedade capitalista, uma sociedade não mais baseada em valores de uso, senão diretamente em valores de troca. Por isso, ela também é conhecida como sociedade de mercado. Nela, o consumo passa a ser determinado pela troca e não mais pelas necessidades básicas de seus membros.

A estrutura da sociedade pauta-se, agora, em laços sociais colocando em segundo plano os laços naturais de até então. É o Contrato Social preconizado por Rousseau (2011), baseado no direito positivo. 0 domínio de uma cultura intelectual é colocado, então, como exigência generalizada a todos os membros da sociedade, sendo a escola o instrumento principal para viabilizar o acesso a este novo tipo de cultura. A nova ordem social surgida após a Revolução Industrial consolida ainda mais essa tendência inicial.

O surgimento da maquinaria e de novas formas de organização do trabalho no interior da nova indústria reduz a necessidade de qualificação específica já que as máquinas desenvolvem a maioria dos serviços manuais, sendo estas a materialização de trabalho intelectual. Similarmente, a ciência transforma-se, de potência intelectual em potência material. 
Assim, Saviani (2007, p. 158) observa que:

[...] o fenômeno da objetivação e simplificação do trabalho coincide com o processo de transferência para as máquinas das funções próprias do trabalho manual. Desse modo, os ingredientes intelectuais antes indissociáveis do trabalho manual humano, como ocorria no artesanato, dele destacam-se, indo incorporar-se às máquinas. Por esse processo, dá-se a mecanização das operações manuais, sejam elas executadas pelas próprias máquinas ou pelos homens, que passam a operar manualmente como sucedâneos das máquinas.

Para adaptar os agora operários da indústria moderna, a burguesia teve de universalizar a escola primária. Os indivíduos, familiarizando-se com os códigos formais, capacitaramse para o processo produtivo. Já que "a máquina viabilizou a materialização das funções intelectuais no processo produtivo, a via para objetivar-se a generalização das funções intelectuais na sociedade foi a escola" (Idem, p. 159). Porém, o sistema de ensino bifurcouse entre escolas de formação geral e escolas profissionais. Embora sobre a base comum da escola primária, ainda existia a necessidade de uma qualificação específica para as tarefas operacionais além da execução das máquinas, como a manutenção, o reparo, o desenvolvimento, etc.

A escola, que antes estava totalmente separada do processo produtivo, após a Revolução Industrial, liga-se a ele. Porém, a educação concebida pela burguesia realizouse sobre a base do ensino primário comum, mas não passou da divisão dos homens em dois campos. As profissões manuais requeriam uma formação prática limitada à execução de tarefas mais ou menos delimitadas, dispensando-se o domínio de seus fundamentos teóricos. Por outro lado, as profissões intelectuais requeriam o domínio teórico amplo para preparar as elites e os dirigentes da classe dominante para atuarem em diversos segmentos da sociedade.

Seguindo a linha de pensamento marxista, compreendemos que o trabalho enquanto ato de transformação da natureza, além de inerente ao homem, é o processo-gênese por meio do qual o homem se torna social. A partir dele surgem as demais esferas da vida humana e social, como a própria educação, por exemplo. Essas dimensões da vida humana adquirem uma autonomia relativa, independência ontológica e determinação recíproca para com o complexo do trabalho.

Esse processo se complexifica com a divisão da sociedade em classes sociais e dá um salto qualitativo com o processo de divisão do trabalho, ocasionando o direcionamento cada vez maior das diretrizes educacionais a serviços de determinados interesses de classe, haja vista a expansão da educação profissional no Brasil, em especial nos últimos nove anos.

Tratamos aqui de abordar alguns conceitos chave para compreensão do papel do trabalho na determinação do homem enquanto ser social. Destacamos também a relação que a educação estabelece nesse processo e seu papel preponderante em manter ao longo das gerações as características próprias do gênero produzidas pelo próprio homem. 


\section{CONSIDERAÇÕES FINAIS}

Há um extenso corpo de pesquisas sobre educação profissionalizante, mas, no que diz respeito ao quadro mais recente, de certo modo, os estudos permanecem em uma zona de inteira incipiência. Ainda existe uma lacuna imensa a nos desafiar, mas, supomos que, progressivamente, isso tende a ser superado. Neste trabalho, de alguma maneira, ousamos adentrar essa seara e oferecer uma contribuição à temática, de longe, tanto ampla quanto complexa, sem, evidentemente, ter a intenção de sequer nos aproximar da ideia de esgotar a questão, mas, pelo menos, de sugeri-la e indicá-la.

Reforçamos a importância destes conceitos para situar, de maneira preliminar, o contexto da implementação da Educação Profissional integrada ao Ensino Médio em curso no país. Considerando a posição de nosso país no mercado mundial, acrescentadas as políticas educacionais neoliberais da década de 1990 e não revertidas (para não dizer continuadas) nos anos seguintes, torna-se difícil acreditar em boas intenções para o povo brasileiro no campo da educação pública.

\section{REFERÊNCIAS}

1. ARCARY, V. Existe uma nova classe média no Brasil? . In: Um reformismo quase sem reformas: Uma crítica marxista do governo Lula em defesa da Revolução Brasileira. São Paulo: Editora Instituto José Luís e Rosa Sundermann, 2011.

2. JIMENEZ, Susana; LIMA, Marteana F. de. O complexo da educação em Lukács: uma análise à luz das categorias trabalho e reprodução social. In: Educação em Revista, Belo Horizonte, v. 27, n. 02, p. 73-94, ago. 2011.

3. LESSA, S., TONET, I. Introdução à filosofia de Marx. São Paulo: Expressão Popular, 2008.

4. MARX, K., ENGELS, F. A ideologia alemã. São Paulo: Martins Fontes, 1989.

5. MANACORDA, M. A. Marx e a pedagogia moderna. São Paulo: Cortez, Autores Associados, 1991.

6. PONCE, A. Educação e luta de classes. São Paulo: Cortez, 2005.

7. ROUSSEAU, J. J. Do Contrato Social. São Paulo: Penguin Companhia, 2011.

8. $\quad$ SANTOS, Deribaldo. Graduação tecnológica no Brasil: crítica à expansão do ensino superior não universitário. Curitiba: CRV, 2012.

9. SAVIANI, D. O trabalho como princípio educativo frente às novas tecnologias. In: FERRETTI, C. J. et al. (Orgs.). Novas tecnologias, trabalho e educação: um debate multidisciplinar. Petrópolis: Vozes, 1994. p. 151-168.

10. Trabalho e educação: fundamentos ontológicos e históricos. In: Revista Brasileira de Educação, v. 12, n. 34, p. 152-165, jan./abr. 2007.

11. SUCHODOLSKI, B. A pedagogia e as grandes correntes filosóficas. Lisboa: Livros Horizonte, 1984. 